\title{
Room Temperature Processable Organic-Inorganic Hybrid Photolithographic Materials Based on a Methoxysilane Cross-Linker
}

\author{
By Ji Young PARK and Jin-Baek KIM*
}

A novel room temperature processable organic-inorganic hybrid resist material containing trimethoxysilyl group was synthesized by copolymerization of 3-methacryloxypropyl trimethoxysilane and $\gamma$-butyrolactonyl methacrylate. This new resist system does not need the post-exposure baking step thereby eliminating the post-exposure delay problems. Protons generated from photoacid generators upon UV irradiation initiate the condensation of trimethoxysilyl groups resulting in siloxane networks in the exposed regions of the resist film. The negative-tone siloxane pattern was used as a top imaging layer of a bilayer resist. The initial lithographic evaluation of the resist showed the potential of the new platform for the next generation resist.

KEY WORDS: Photolithography / Bilayer resist / Trimethoxysilane /

Chemically amplified resists utilizing acid-catalyzed reactions have been widely used for the production of integrated circuits. To meet the upcoming demand of next generation lithography, new chemically amplified resist materials should be developed because the common chemically amplified resists suffer from serious problems such as T-top and line-width shift caused by the air-borne contamination and the acid diffusion in the resist films when the post-exposure bake is delayed. These post-exposure delay (PED) problems make it difficult to fabricate fine patterns. ${ }^{1,2}$ To solve these PED problems, various methods have been demonstrated. ${ }^{3,4}$ Reduction of free volume of the resist film, protection by overcoats, filtering the impurities in the enveloping atmosphere, and incorporation of stabilizing additives were carried out. Nonchemically amplified resists also showed potential solutions to the PED problems, ${ }^{5,6}$ though their sensitivities were relatively low.

Photoresists containing silicon have been studied for an imaging layer of a bilayer system. ${ }^{7,8}$ Bilayer resists have several advantages. Because the top imaging layer is very thin, the resist materials of relatively high absorbance can also be used. The anti-reflective bottom planarizing layer diminishes the defects like standing wave effect, which causes irregular line edge profile. Furthermore, bilayer resists need only a small depth of focus and high aspect ratio patterns can be obtained.

The aim of this study is to design a new resist system that does not need the post-exposure baking step and contains silicon for a bilayer resist. Trimethoxysilane was selected to provide those effects. In the presence of moisture and catalyst, alkoxysilanes undergo cross-linking reactions at room temperature to form a stable siloxane-linked network, which results in the desired solvent resistance. ${ }^{9}$ Since trimethoxysilyl groups can cross-link at room temperature, there is no necessity for the post-exposure baking step that is the cause of acid diffusion.
And it contains sufficient silicon content for the top imaging layer in the bilayer system. In this paper, we report the synthesis and lithographic evaluations of the novel organicinorganic hybrid resist that contains trimethoxysilane crosslinkers.

\section{EXPERIMENTAL}

\section{Materials}

3-Methacryloxypropyltrimethoxysilane (MPMS) was purchased from Aldrich Chemical Company and used without further purification. $\gamma$-Butyrolactonyl methacrylate (GBLMA) was purchased from ENF Technology Company. 2,2'-Azobisisobutyronitrile (AIBN) was purchased from Junsei Chemical Company and purified by recrystallization in methanol.

\section{Polymerization}

All polymers were prepared by free radical polymerization in sealed ampoules. Monomers and $2 \mathrm{~mol} \%$ AIBN were dissolved in THF, and the resulting mixture was heated at $65^{\circ} \mathrm{C}$ for $6 \mathrm{~h}$. The ratio of monomer weight relative to the weight of solvent is 0.5 in all cases. After the polymerization, the solutions were diluted with THF and precipitated into petroleum ether. The precipitated polymers were collected by filtration and washed with the precipitating solvent. After drying under vacuum for $24 \mathrm{~h}$, white powdery materials were obtained.

\section{Acid-Catalyzed Hydrolysis and Condensation}

For the investigation of FT-IR spectra, a solution was prepared by dissolving $0.2 \mathrm{~g}$ of the polymer in $1 \mathrm{~mL}$ of THF with $0.007 \mathrm{~g}$ of triphenylsulfonium triflate (TPSTf) and spincoated on a $\mathrm{NaCl}$ cell. FT-IR spectra were compared before 
and after exposure $\left(\right.$ dose $\left.=13 \mathrm{~mJ} \cdot \mathrm{cm}^{-2}\right)$. For the investigation of solid state ${ }^{29} \mathrm{Si} \mathrm{NMR}$ spectra, a solution of $0.5 \mathrm{~g}$ of the polymer in $10 \mathrm{~mL}$ of THF and 2 drops of $\mathrm{HCl}$ was stirred for $3 \mathrm{~min}$, and precipitates were filtered and washed several times with THF and methylenechloride, then dried. The solid state ${ }^{29} \mathrm{Si}$ NMR spectra of the resulting solid were compared with that of the untreated polymer.

\section{$\mathrm{O}_{2}$ Reactive Ion Etching (RIE)}

The $\mathrm{O}_{2}$-RIE rate was obtained by measuring the remained thickness of the polymer film after certain time of the reactive ion etching process. The ion etching process was applied using a parallel plate reactor at 337 mTorr pressure, an oxygen flow rate of $30 \mathrm{sccm}$ and RF power of $100 \mathrm{~W}$.

\section{Lithographic Evaluation}

Samples were prepared by spin coating a $15 \mathrm{wt} \%$ resist solution of the polymer in cyclopentanone on a bare silicon wafer. The planarizing layer was formed by spin coating of the novolac resist solution onto the silicon wafer. Flood exposure of deep UV light was carried out over the planarizing layer, which was further hard baked at $200^{\circ} \mathrm{C}$ for $10 \mathrm{~min}$. A $10 \mathrm{wt} \%$ resist solution of the polymer in cyclopentanone was spin coated over this planarizing layer. Exposure was carried out on a deep UV exposure system with a high-pressure mercury-xenon lamp and a filter transmitting light between 220 and $260 \mathrm{~nm}$.

\section{RESULTS AND DISCUSSION}

\section{Polymerization}

The overall scheme for the synthesis of the polymer is given in Scheme 1. Since the homopolymer of MPMS is a viscous liquid, a polar monomer, GBLMA, was incorporated to get the desired polymer as a solid at room temperature. The copolymers of MPMS with GBLMA were copolymerized by free radical polymerization, and the results are summarized in Table I. The mole fractions of MPMS in polymers were ranged from 0.28 to 0.55 based on ${ }^{1} \mathrm{H} \mathrm{NMR}$ analysis. The number average molecular weights of polymers were in the range of $4930-7650 \mathrm{~g} \cdot \mathrm{mol}^{-1}$ and the polydispersity indices were $1.92-$ 2.06. The polymerization yields were $69-74 \%$. The $\mathrm{T}_{\mathrm{g}}$ of the polymers were ranged around $50.3-51.7^{\circ} \mathrm{C}$ which are higher than the processing temperature $\left(20-25^{\circ} \mathrm{C}\right)$. Since trimethoxysilane-containing materials are moisture sensitive, the obtained polymers should be stored under dry conditions.

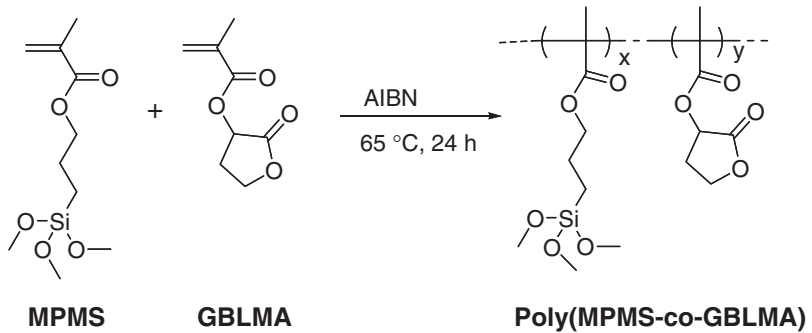

Scheme 1. The synthetic scheme of poly(MPMS-co-GBLMA).
Table I. Radical polymerization of MPMS and GBLMA

\begin{tabular}{cccccccc}
\hline Polymer & $\begin{array}{c}\text { Monomer } \\
\text { feed ratio } \\
\text { MPMS:GBLMA }\end{array}$ & $\begin{array}{c}\text { Copolymer } \\
\text { composition }^{\mathrm{a})} \\
\text { MPMS:GBLMA }\end{array}$ & $\begin{array}{c}\mathrm{Si} \\
\text { content } \\
\text { wt } \%\end{array}$ & $\begin{array}{c}\text { Yield } \\
\%\end{array}$ & $\begin{array}{c}\left.\mathrm{T}_{\mathrm{g}}{ }^{\mathrm{b}}\right) \\
{ }^{\circ} \mathrm{C}\end{array}$ & $\mathrm{M}_{\mathrm{n}}{ }^{\mathrm{c})}$ & $\mathrm{MWD}^{\mathrm{c})}$ \\
\hline P1 & $30: 70$ & $28: 72$ & 4.1 & 74 & 50.3 & 4,930 & 2.04 \\
P2 & $40: 60$ & $36: 64$ & 5.1 & 69 & 51.2 & 6,970 & 1.92 \\
P3 & $50: 50$ & $55: 45$ & 7.2 & 71 & 51.7 & 7,650 & 2.06 \\
\hline
\end{tabular}

a) Determined by integration of the corresponding peaks in the ${ }^{1} \mathrm{H}$ NMR

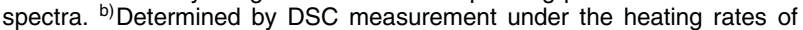
$10^{\circ} \mathrm{C} \cdot \mathrm{min}^{-1}$ under nitrogen. ${ }^{\mathrm{c})}$ Measured by GPC using THF as eluent and polystyrene as standard.

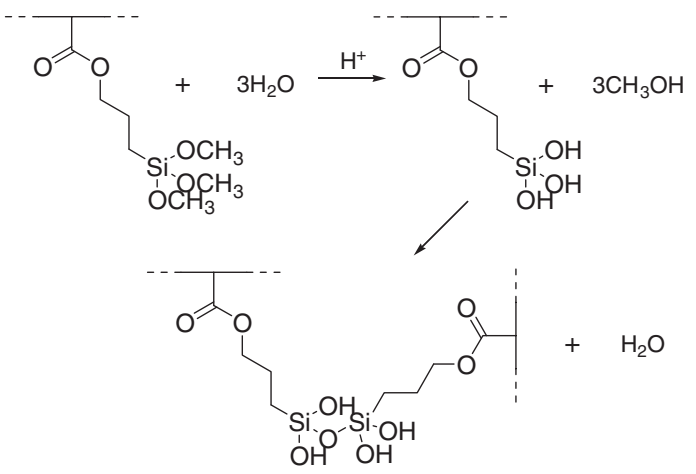

Figure 1. The cross-linking mechanism of trimethoxysilane.

\section{Acid-Catalyzed Hydrolysis and Condensation}

Upon irradiation, protons generated from photoacid generators (PAGs) catalyze the hydrolysis of methoxysilane groups to silanol, followed by condensation of the silanol groups. All of those reactions occur at room temperature with high sensitivity. The plausible mechanism leading to coupling between the methoxysilane groups is given in Figure $1 .{ }^{10,11}$ As the hydrolysis and the condensation take place during the irradiation of UV light, the PED problems can be eliminated.

The reaction of methoxysilanes was studied using FT-IR spectroscopy of the thin film of $\mathbf{P 3}$ on a $\mathrm{NaCl}$ cell. After UV exposure, the peaks at $3500 \mathrm{~cm}^{-1}$ and $950 \mathrm{~cm}^{-1}$ were appeared, which are assigned to $\mathrm{SiO}-\mathrm{H}$ and $\mathrm{Si}-\mathrm{OH}$ stretching, respectively. The peaks at $820 \mathrm{~cm}^{-1}$ and $1085 \mathrm{~cm}^{-1}$ which correspond to $\mathrm{SiO}-\mathrm{CH}_{3}$ were reduced as shown in Figure 2. ${ }^{12,13}$ The reaction was also confirmed by solid state ${ }^{29} \mathrm{Si}$ NMR spectroscopy of P3. As shown in Figure 3, two new peaks from $\mathrm{T}^{1}$ and $\mathrm{T}^{2}$ structures of siloxanes at -50 and $-57 \mathrm{ppm}$ appeared in the acid-treated sample. ${ }^{14} \mathrm{~T}^{\mathrm{n}}$ corresponds to $\mathrm{R}^{\prime}-\mathrm{Si}$ $(\mathrm{OSi})_{\mathrm{n}}(\mathrm{OR})_{3-\mathrm{n}}$. From these results, the solubility change of the resist film in the exposed region is attributed to the formation of siloxane linkages.

\section{$\mathrm{O}_{2}$ Reactive Ion Etching (RIE)}

Oxygen reactive ion etching $\left(\mathrm{O}_{2}-\mathrm{RIE}\right)$ resistance is an essential criterion for a resist material to be used as a bilayer resist. Table II and Figure 4 show the results of $\mathrm{O}_{2}$-RIE of polymers (P1-P3) and novolac resin (planarizing bottom layer). Novolac resin that contains no silicon was completely etched in $191 \mathrm{~s}$, whereas the remained thicknesses of P1-P3 were 20- 


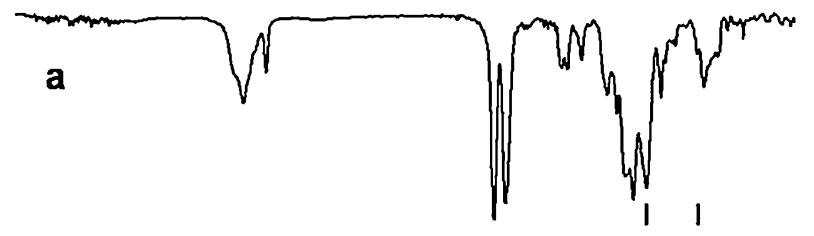

$1085,820\left(\mathrm{Si}-\mathrm{OCH}_{3}\right)$

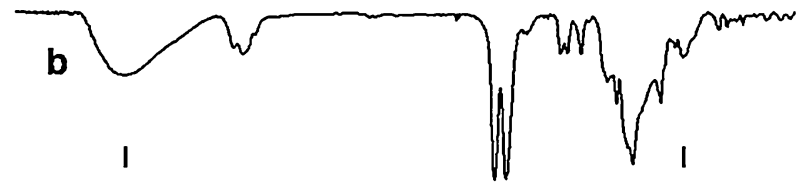

$3500,950(\mathrm{SiO}-\mathrm{H})$

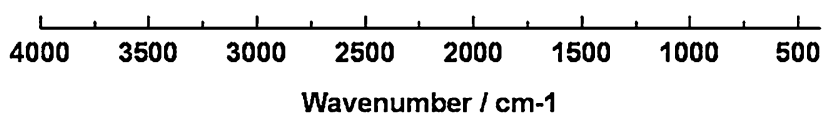

Figure 2. FT-IR spectroscopic change of poly(MPMS-co-GBLMA) a) before and b) after UV irradiation.
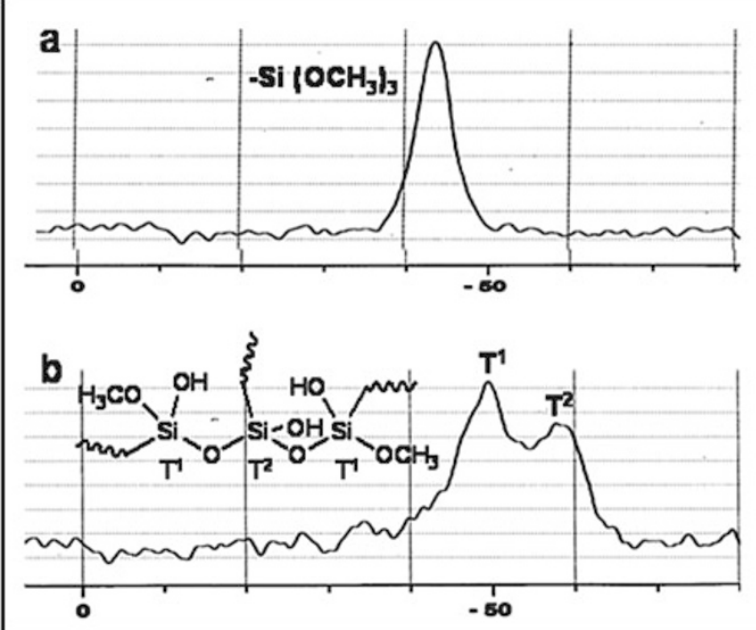

Figure 3. Solid state ${ }^{29} \mathrm{Si}$ NMR spectrum change of poly(MPMS-co-GBLMA) a) before and b) after acid treatment.

$40 \%$ of their initial thicknesses after $\mathrm{O}_{2}$-RIE for $420 \mathrm{~s}$. As the silicon content increases, the remained film thickness gradually increases. These results show that poly(MPMS-co-GBLMA) has sufficient $\mathrm{O}_{2}$-RIE resistance even though the silicon contents are relatively low (4.1-7.1 wt \%) compared to the reported value ( $9 \mathrm{wt} \% \mathrm{Si}$ content) ${ }^{7}$

FT-IR spectroscopy was used for detecting the formation of the siloxane layer during the oxygen plasma etching. Figure 5 show the FT-IR spectra of P2 before (A) and after etching (B). After $\mathrm{O}_{2}$ etching, peaks at $1250-1075 \mathrm{~cm}^{-1}$ attributed to the Si-O-Si structure become dominant. On the other hand, peaks from organic moiety become significantly weaker, $2946 \mathrm{~cm}^{-1}$ attributed to $\mathrm{C}-\mathrm{H}$ stretching and 1790 and $1735 \mathrm{~cm}^{-1}$ attributed to $\mathrm{C}=\mathrm{O}$ stretching. This study indicates that most organic materials are removed and a siloxane layer is formed during $\mathrm{O}_{2}$ etching.
Table II. The results of oxygen reactive ion etching

\begin{tabular}{cccc}
\hline Materials & $\begin{array}{c}\text { Before RIE } \\
(\AA)\end{array}$ & $\begin{array}{c}\text { After RIE } \\
(\AA)\end{array}$ & $\begin{array}{c}\text { Etching Time } \\
(\mathrm{s})\end{array}$ \\
\hline P1 & 4645 & $934(20 \%)^{\mathrm{a}}$ & 420 \\
P2 & 4394 & $1305(30 \%)^{\mathrm{a}}$ & 420 \\
P3 & 3706 & $1499(40 \%)^{\mathrm{a}}$ & 420 \\
Novolac & 6009 & 0 & $191^{\mathrm{b}}$ \\
\hline
\end{tabular}

a) The remained thickness \% compared to initial thickness. b) The time needed for etching the film completely.

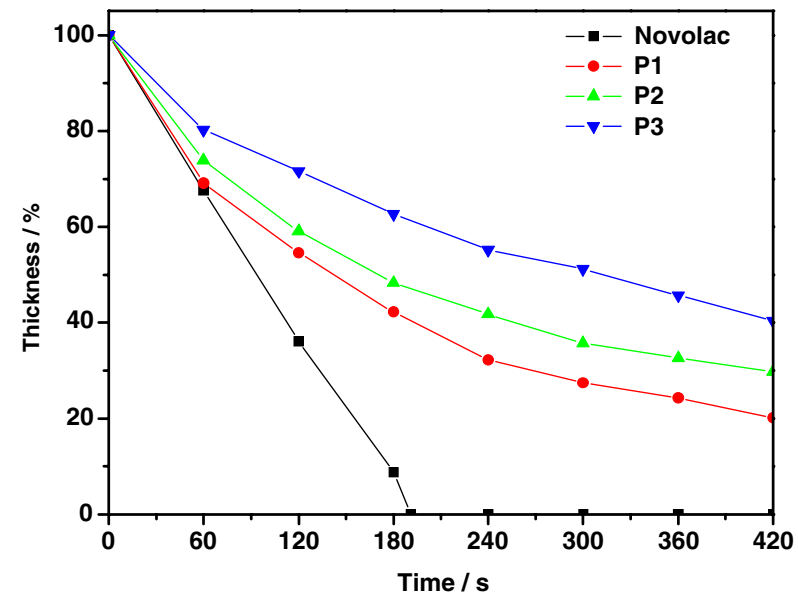

Figure 4. The thickness profiles of polymer films during oxygen reactive ion etching.

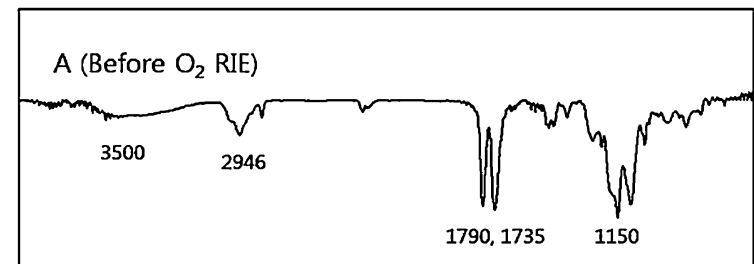

B (After $\mathrm{O}_{2}$ RIE)

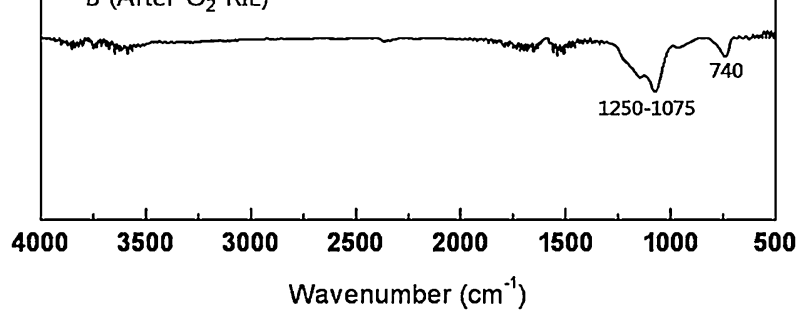

Figure 5. FT-IR spectroscopic change of $\mathrm{P} 2$ a) before and b) after $\mathrm{O}_{2}$ etching.

\section{Lithographic Evaluation}

The UV absorbance of P3 at $193 \mathrm{~nm}$ is $0.3 \mu \mathrm{m}^{-1}$ and this value indicates that $\mathrm{P} 3$ is relatively transparent compared to other 193-nm resist materials, therefore it can be used as a 193$\mathrm{nm}$ resist material. Lithographic evaluation was performed on P3 as both single layer and bilayer resists. The high quality and uniform film was obtained from a $15 \mathrm{wt} \%$ solution of P3 in cyclopentanone by spin coating on a bare silicon wafer. The unexposed regions of the resist film were dissolved using 


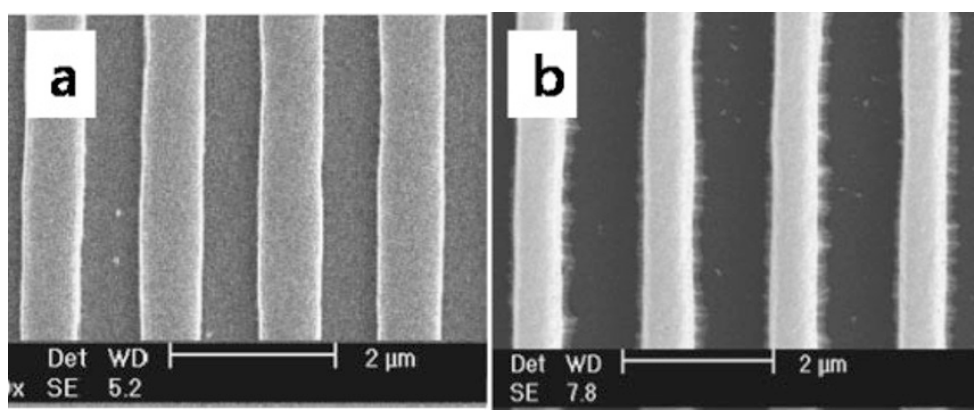

Figure 6. Scanning electron micrograph of the $0.7 \mu \mathrm{m}$ line and space negative tone image formed with P3 as a single layer resist (a) and as a bilayer resist after $\mathrm{O}_{2}$ plasma etching (b).

dichloromethane as a developer. For a film of $0.3 \mu \mathrm{m}$ thickness, $8 \mathrm{~mJ} \cdot \mathrm{cm}^{-2}$ dose was used. For the lithographic evaluation as an imaging layer of the bilayer resist system, a film of $0.2 \mu \mathrm{m}$ thickness was formed from a $10 \mathrm{wt} \%$ solution of P3 in cyclopentanone on top of the planarizing novolac film of $0.6 \mu \mathrm{m}$ thickness. Lithographic evaluation was carried out with a $8 \mathrm{~mJ} \cdot \mathrm{cm}^{-2}$ dose and the unexposed regions were developed with dichloromethane. The wet-developed pattern of the imaging layer was anisotropically transferred to the underlying planarizing layer by $\mathrm{O}_{2}$ plasma. Figure 6 shows the scanning electron micrograph of the $0.7 \mu \mathrm{m}$ line and space negative tone image formed with P3 as a single layer resist (a) and as a bilayer resist after $\mathrm{O}_{2}$ plasma etching (b).

The results show this new platform has the potential for the next generation resists, although further optimization is necessary. The initial lithographic studies have shown the feasibility of this hybrid polymer system to be used as both single layer and bilayer resists.

\section{CONCLUSION}

We designed and synthesized a new type of organicinorganic hybrid resists containing a methoxysilane crosslinker, poly(MPMS-co-GBLMA), for deep UV lithography. The resist formulated with this polymer does not need the postexposure baking step for lithographic evaluation thereby eliminating the post-exposure delay problems. Protons generated from PAGs upon UV irradiation initiate the condensation of methoxysilane groups resulting in siloxane networks in the exposed regions of the resist film creating negative-tone images. The formed siloxane enables the resist to be used as a bilayer resist.
Acknowledgment. The authors would like to acknowledge the financial support of the Brain Korea 21 (BK21) project.

Received: February 27, 2008 Accepted: April 14, 2008 Published: June 4, 2008

\section{REFERENCES}

1. P. I. Tattersall, D. Breslin, S. M. Grayson, W. H. Heath, K. Lou, C. L. McAdams, D. McKean, B. M. Rathsack, and C. Grant Willson, Chem. Mater. 16, 1770 (2004).

2. E. Reichmanis, F. Houlihan, O. Nalamasu, and T. Neenan, Chem. Mater. 3, 394 (1991).

3. H. Ito, G. Breyta, R. Sooriyakumaran, and D. Hofer, J. Photopolym. Sci. Technol. 8, 505 (1995).

4. Y. Kawai, A. Otaka, A. Tanaka, and T. Matsuda, Jpn. J. Appl. Phys. Part 1 33, 7023 (1994).

5. J.-B. Kim and K.-S. Kim, Macromol. Rapid. Commun. 26, 1412 (2005).

6. J.-B. Kim, R. Ganesan, J.-H. Choi, H.-J. Yun, Y.-G. Kwon, K.-S. Kim, and T.-H. Oh, J. Mater. Chem. 16, 3448 (2006).

7. E. Tegou, V. Bellas, E. Gogolides, and P. Argitis, Microelectron. Eng. 73-74, 238 (2004).

8. V. Bellas, E. Tegou, I. Rapitis, E. Gogolides, P. Argitis, H. Iatrou, N. Hadjichristidis, E. Sarantopoulou, and A. Cefalas, J. Vac. Sci. Technol. B 20, 2902 (2002).

9. I. Marcu, E. S. Daniels, V. L. Dimonie, C. Hagiopol, J. E. Roberts, and M. S. El-Aasser, Macromolecules 36, 328 (2003).

10. Y.-T. Shieh and K.-I. Hsiao, J. Appl. Polym. Sci. 70, 1075 (1998).

11. S. A. Pellice, R. J. J. Williams, I. Sobrados, J. Sanz, Y. Castro, M. Aparicio, and A. Duran, J. Mater. Chem. 16, 3318 (2006).

12. A. Fidalgo and L. M. Ilharco, J. Non-Cryst. Solids. 283, 144 (2001).

13. A. Chmel, E. K. Mazurina, and V. S. Shashkin, J. Non-Cryst. Solids 122, 285 (1990).

14. M. B. Salon, G. Gerbaud, M. Abdelmouleh, C. Bruzzese, S. Boufi, and M. N. Belgaceml, Magn. Reson. Chem. 45, 473 (2007). 